\title{
¿Hacia dónde va el ESTE? y ¿hacia dónde va el OESTE?
}

Francisco Javier Ibisate

Allá, por el siglo 17 Galileo Galilei (1564-1642) fue condenado por el Santo Oficio al sostener la teoría de Copérnico sobre los movimientos en el universo: ya no era el sol quien giraba alrededor de la tierra, sino la tierra alrededor del sol. Para quienes veian un dogma en cada versículo de la Biblia la tesis de Galileo era la herejía. Pero lo más intresante en la herejía de Galileo era preguntarse; y ¿alrededor de quién se mueve el sol? -Era el plus-ultra de la ciencia. Cuatro siglos más tarde vuelven a aparecer los dogmas, y por lo tanto los herejes, frente a otra clase de movimientos. ¿Es el capitalismo el que se mueve alrededor del socialismo, o es el socialismo el que da vueltas alrededor del capitalismo? - Las dos preguntas han tenido sus dogmáticos, sus herejes y su Santo Oficio. Cuando en los anos de $1930 \ldots$ el capitalismo se vió arrastrado por su treceava y más profunda crisis mundial el socialismo emergente profetizó el comienzo del final: el capitalismo se desintegrará en el presente siglo absorbido en la óbita de las economias planificadas. El epicentro se trasladaba al Este, y hacia allá tendria que moverse el Oeste y el Sur.

Sesenta anos más tarde presenciamos en forma rápida e inesperada serios trastornos en este universo económico, y los semáforos publicitarios cambian del rojo al verde. En los diarios occidentales se anuncia: "el Este camina hacia el Oeste". Ahora es el Santo Oficio del capitalismo quien dicta sentencia inapelable: el socialismo está muerto y sepultado. La historia ha demostrado que "el comunismo es la via más larga para pasar del capitalismo al capitalismo". Por lo visto a cada dogmático y a cada hereje le tocan en suerte sus dias alegres y 
sus dias tristes. Pero la historia es algo más serio y más resistente que los dogmas y las herejias económicas del momento.

Volviendo a Galileo y a Copérnico to más científico parece ser el preguntarse: ¿alrededor de quién se mueven el Este y el Oeste, el capitalismo y el socialismo? - La pregunta es razonable históricamente, aunque bastante imperfecta conceptualmente. En realidad to que llamamos Este y Oeste representa sólo la tercera parte del universo económico humano; y al interior de to que entendemos por capitalismo y socialismo se han planteado problemas y cuestionamientos que ninguno de los dos ni los han resuelto y quizá ni lo habian imaginado en su agenda de trabajo. Una de las herejias más torpes y mediocres es reducir la controversia del capitalismo-socialismo a la simple alternativa de plan o mercado; esta teoría no penetra más allá de la corteza del planeta económico. La pregunta más completa, y también más árdua de responder, es ¿de dónde y hacia dónde se mueve la historia del siglo $\mathrm{XX}$, la historia del capitalismo y del socialismo?

\section{El sIglo XXI comlenza en 1989: ¿se replte el Kondratlef?}

En un reciente coloquio tenido en la Sorbona de París (20-2-90), en el que participaron treinta figuras representativas del quehacer político y económico del Este y Oeste Europeo, el Primer Ministro francés, Michel Rocard, inicia su exposición con estas palabras: "Los historiadores nos han ensenado que el siglo XX comenzó en 1914. Sin duda a partir de ahora debemos decir que 1989 marcó el comienzo del siglo XXI"1. Este coloquio de París, precedido por la macroencuesta realizada en ocho paises del Este y Oeste Europeo, así como el Seminario tenido en Moscú (junio-1989), dedicado todos ellos al tema de la post-Perestroika y el futuro europeo, van a servir de telón de fondo al presente comentario. Pero hay lugar que hacer un intervalo previo, ya que nuestro interés es preguntarse de dónde y hacia dónde se mueven tanto el capitalismo como el socialismo. Cuando el Primer Ministro francés dice que el siglo $X X$ se inicia en 1914 y que el siglo XXI comienza en 1989, el estudioso o simple aficionado a los grandes movimientos económicos siente que le están planteando un curioso interrogante: ¿será que el siglo $X X$ se está moviendo con iguales perfiles que el siglo $X I X$ ? En economia no hay leyes naturales que generen movimientos cíclicos repetidos en determinados períodos de tiempo; pero se vienen dando sorpresivas coincidencias en el pasado y presente siglo, que han marcado los vaivenes primero del capitalismo y luego del socialismo. Por ello antes de preguntarnos hacia dónde va el siglo XXI puede resultar interesante contemplar los pertiles de los dos siglos precedentes. 
En una visión secular, es decir que abarca todo un siglo, la evolución de las grandes variables económicas han formado las llamadas Ondas-Largas, o movimientos del Kondratier; sus ondulaciones se presentan de la siguiente forma a lo largo del siglo XIX. De 1790 a 1815 (fin de las guerras de Napoleón) se inicia un rápido crecimiento de la revolución industrial; onda larga al alza. De 1815 hasta casi 1850 asistimos a un crecimiento frenado y agitado de las economias nacionales: onda larga a la baja. A partir de 1850 hasta 1872 se reinicia un segundo crecimiento acelerado de las economias de vanguardia: segunda onda larga al alza. Desde 1872 (guerra francoprusiana) hasta 1890 vuelven a aparecer más años de crecimiento frenado que de expansión, acompanados de convulsiones sociales recogidos en la primera encíclica "Renum Novarum" (Los Nuevos Acontecimientos...). Por tercera vez, a partir de 1890 las estadisticas de la revolución industrial marcan una febril onda larga al alza que se estrella en la primera guerra mundial, 1914-1919.

De acuerdo a la cita de Michel Rocard, ahi comienza el siglo XX. Casualidad y no mecanismos económicos, el siglo XX repite aproximadamente las ondulaciones del siglo $X I X$, con una variante: ahora son el capitalismo y el socialismo los que subirán y descenderán casi al unisono. A partir de 1914-1919 el capitalismo se ennumba, bandazo tras bandazo, hasta su más profunda crisis que transciende los anos de 1930, mientras que emerge con todo vigor el socialismo. Habrá que esperar, una vez más, hasta 1950, ya terminada y restaurada la segunda guerra mundial, para que se reinicie a la par, en el capitalismo y en el socialismo, la más vigorosa onda larga del crecimiento económico que en veinte anos multiplicó por cuatro el producto mundial. Nueva coincidencia secular, a los cien anos de 1870 , tanto en el capitalismo como en el socialismo se da un fuerte viraje hacia una onda larga de contracción económica hasta nuestros dias. En el bloque occidental se resiente una nueva enfermedad, la estanflación; en el bloque del Este se adentran en la fase del "estancamiento de la eraBresnev", y que no termina con Bresnev.

Este breve recorrido de coincidencias seculares entre el siglo $X \mid X$ y XX no pretende ser una explicación de hechos y problemas; sólo se han mencionado fechas y no razones. Pero no dejan de ser llamativas las coincidencias; los perfiles superiores o fechas de transición de la expansión a la contracción son llamativas: 1815 - 1870 - 1915 - 1970. $Y$ no lo son menos las fechas de los perfiles inferiores que marcan la transición de la contracción hacia la expansión: 1790-1850-1890-19501990. Una vez consolidado el socialismo, a partir de 1950 , se ha convertido en companero de viaje del capitalismo en el gran movimiento de 
expansión y de contracción económicas. ¿Quién mueve a los que se mueven? Por supuesto que la pregunta no pretende insinuar que el siglo XXI será una repetición mecánica del presente y pasado siglo, sino simplemente decir que los dos se mueven. Esperamos y deseamos que el siglo XXI sea algo bien diferente. Esperamos que la pregunta no vuelva a ser: ies el capitalismo el que da vueltas alrededor del socialismo, o es el socialismo quien gira alrededor del capitalismo? Esta fue la pregunta desde la Rerum Novanum de los anos 1890 hasta la Perestroika de los años 1990. Y ¿cuál fue la respuesta? La peor respuesta que se ha podido dar: las guerras y la carrera armamentistica hasta la amenaza real de acabar con toda la humanidad, la contendiente y la inocente, que es la peor malparada en todas las guerras. Lo que más se ha desarrollado ha sido la guerra y todos sus subproductos de violencia e irrespeto social. Se ha conseguido también que las naciones se agoten, se endeuden, y que se vayan esquilmando las riquezas de nuestro universo material. Con toda razón los ecologistas nos cuestionan: el problema del mundo actual no es producir más, sino producir menos para no agotar la fuente de nuestra riqueza. Al acabar el siglo XX y ojalá iniciar ya el siglo XXI, al capitalismo y al socialismo se les pide que produzcan menos de to que más han producido: guerra y violencia. $Y$ se les nuega que produzcan más de to que menos han producido: seguridad, esperanza y democracia.

\section{II. ¿Hacla dónde van el Este y el Oeste?}

La historia del siglo XX nos demuestra que el Este y el Oeste, el capitalismo y el socialismo se han movido a la par, pero no en la mejor dirección, de acuerdo a cómo lo percibimos desde nuestro gran tercer mundo. Por ello nos hacemos la pregunta: ¿hacia dónde evolucionan el Este y el Oeste? Tenemos fundados temores que al caminar el Este hacia el Oeste y el Oeste hacia el Este, todo ello a niveles del hemisferio-Norte, nos dejen fuera del radar a los residentes del hemisferio-Sur. Sin embargo, hay sus razones válidas para alentar sanas esperanzas. Del enfrentamiento armado parece que se evoluciona hacia un acercamiento económico; de los distanciamientos ideológicos hacia un diálogo más cercano; de la divergencia en los sistemas hacia la convergencia en mayor democracia. Por lo menos ésto es to que puede deducirse, en la era de la post-perestroika, de los coloquios, seminarios, discursos y macroencuestas realizados en el pasado y presente ano en varios paises del Este y Oeste europeo. Europa, el "hogar-común" como la llamó N. Gorvachov en el Cap. $6^{0}$ de su Perestroika, pasa a ser el punto focal de las expectativas mundiales. 
Los titulares de los medios de comunicación nos van dando las piezas que pueden armar el complejo mosáico: "El imperio se hace la Perestroika; Gorbachov, un líder para una reforma histórica; a la búsqueda del equilibrio entre mercado y socialismo; el Este va hacia el Oeste; el siglo XXI ha comenzado ya; unificar no es reunificar Alemania; ni comunismo ni capitalismo; conservadores en to económico, socialdemócratas en to demás; húngaros y polacos quieren integrarse en un gran mercado común europeo..." "Por supuesto, se pueden multiplicar los titulares, con mayúscula, extractados de tres acontecimientos a que quiere referirse el presente comentario.

El seminario celebrado en Moscú, junio de 1989, sobre el presente y el futuro de la Perestroika, reunió a más de treinta escritores, economistas, historiadores y políticos soviéticos junto con una docena de observadores de la prensa occidental. Este seminario tuvo tres partes: la primera dedicada a las cuestiones políticas; la segunda a la situación económica, y la tercera se centró en el papel de la cultura y de la creación intelectual en la etapa reformista. El segundo acontecimiento, que sirve a ir armando el mosaico europeo y trans-europeo, es la macroencuesta europea realizada en ocho paises del Este y Oeste ${ }^{3}$. La encuesta pasada en el mes de enero-1990 ha servido para ser debatida en el coloquio sostenido en la Sorbona de París, a partir del 20 de febrero de 1990 con participación de unos treinta políticos, historiadores, economistas de paises del Este-Oeste europeo, amén de la presencia de cinco grandes diarios occidentales. ¿Qué tienen de importante estos eventos?; ¿de qué dialogan los hombres del Este y del Oeste europeo?

A primera vista y a base de repetir que el Este camina hacia el Oeste y por lo tanto el Oeste va hacia el Este llegamos a la conclusión de que la nueva Europa se reduce a un nuevo Mercado Común de $\mathbf{8 0 0}$ millones, a una nueva riada de inversiones, créditos y donaciones, esta vez orientales (Japón) y occidentales. Si bien ésto es cierto, no es más que media verdad, sobre todo si reducimos el problema y la solución a que ahora los socialismos reales del Este cambian un modelo de planificación económica por un modelo de mercado. Así parece estarse interpretando estos cambios en nuestro pequeno occidente centroamericano. En reciente artículo4, dedicado al tema de la post-perestroika, utilizando los juicios y análisis de $M$. Gorbachov y, entre otros autores socialistas, los aportes de dos hombres prácticos exilados y hoy rehabilitados, Ota Sik (Chechoeslovaquia) y W. Brus (Polonia) se ha tratado de mostrar que las raices de los problemas económicos no son fundamentalmente errores del modelo planificado, sino que han de buscarse en la estructuración oligárquica del poder, en los dogmatis- 
mos y en la corrupción creados por los detentores del mismo poder y en la alienación psicológica generalizada en una sociedad donde ni desde arriba ni desde abajo habia lugar para decir la verdad.

En este sentido resulta enriquecedor escuchar a los participantes de estos seminarios o coloquios sostenidos recientemente en Moscú y en Paris, al igual que las expectativas despertadas por la encuesta macroeuropea. La sinceridad de las participaciones se equipara a la sinceridad con que se expresa M. Gorvachev en su Perestroika. La intención y la finalidad no es simplemente satisfacer una sana curiosidad sobre los problemas sociopolíticos y culturales que allá se expresan, sino escuchar estas intervenciones como dichas en y para nuestros paises. Las críticas y las expectativas de la nueva Europa son las críticas y las expectativas de nuestro tercer mundo. Si en 1990 comienza el siglo XXI no podemos quedar rezagados en el nuevo movimiento iniciado con la post-perestroika.

\subsection{Un objetlvo común: vencer la Intolerancla}

Este es uno de los subtítulos y conclusiones del Foro de Moscú (junio-1989). Es normal que, participando en este seminario escritores, economistas, historiadores y políticos soviéticos, el ataque a la intolerancia presente ámbitos diferentes aunque siempre convergentes.

\section{La Intolerancla polítlca}

"El imperio se hace la perestroika" sirve de frontispicio al gran tema del foro de Moscú. Una vez que autorizados historiadores como Yuri Afasaniev, Roy Medvedez... han exfoliado de los archivos históricos hechos y secretos hasta entonces ocultos surge con fuerza una primera reacción contra la intolerancia del "imperio". Stalin pudo tener sus razones, pero fueron más las sinrazones, para montar el imperio panruso. El problema de las nacionalidades, los enclaves étnicos en diferentes repúblicas, la forzada imposición lingüística a más de cien regiones distintas, sin entrar en los tristes recuerdos de las purgas y el terror, son hoy dia para M. Gorbachov dolores tan fuertes como la desnutrición económica de toda la Unión. Renace el espíritu nacionalista al interior de la URSS y en el resto de los países satélites; prueba de ello la multiplicidad de partidos nacionalistas presentes en las recientes elecciones celebradas en todos estos paises. Tema a comentar en la interpretación de la macroencuesta europea. El hecho más aireado en el exterior es todo el movimiento independentista de las repúblicas del Báltico (Lituania, Estonia, Letonia) y los conflictos de Arzeibaijan. Pero no es éste un problema único de la URSS, como 
puede apreciarse en el delicado tratamiento que se viene dando al tema de la "unidad alemana". Bronislav Gemerek, de Solidaridad polaca, agradece a Willy Brandt por "su distinción entre unidad alemana y reunificación de una vieja unidad política". Es clara la referencia al temible imperio nazi. Por ello, aunque la nueva Alemania se convierta en el centro de la nueva Europa, lo que se busca con la unificación no es una Europa alemana sino una Alemania a la europea.

El no a la intolerancia del imperio ¿no se escucha también desde este lado del Atlántico? También los EE.UU. deben meditar el Cap. $7^{\mathbf{9}}$ de Perestroika: "Ni la Unión Soviética, ni los Estados Unidos, ni ningún otro pais puede considerar al mundo o cualquier parte de él, como objeto de explotación, ni siquiera bajo pretexto de los intereses nacionales" (p. 250). Está bien que el presidente Bush aconseje a $M$. Gorachov cómo mantener una postura democrática frente a los movimientos independentistas de las repúblicas bálticas. Pero ¿no le puede regresar el boomerang a la Casa-Blanca?

Vencer la intolerancia tiene una segunda dimensión política al interior del bloque-Este. La teoria de la "coexistencia pacífica", hasta bien adentrados en la década de 1980, se fundamentaba en la doble tesis: el principios de la solidaridad internacional de los paises del bloque bajo la hegemonía del Estado más fuerte y patria de la revolución socialista mundial. En consecuencia, el principio de solidaridad internacional, inscrito en el Art. 28 de la Constitución Soviética, se debia entender de parte de los países adscritos al bloque como "soberania limitada". Es decir, la causa común era la defensa de los logros del socialismo en todos y cada uno de los paises del bloque. Se legitimarán de este modo las intervenciones o las invasiones en paises como Hungria, Polonia, Checoeslovaquia (en los años 1955-1956 de la era-Krutchev), la invasión a Checoeslovaquia, 1968, v-luego a Afganistán, 1979, (en la era-Bresnev).

Es claro que con M. Gorbachov se ha iniciado un cambio tal como se aprecia en el texto de la Declaración Soviético-Yugoeslava, del 18 de marzo de 1988. "Yugoeslavia y la URSS confirman su disposición a desarrollar y enriquecer sustancialmente sus relaciones desde el principio de independencia, igualdad y no ingerencia, la responsabilidad de cada partido a la clase obrera y al pueblo de su propio pais; el respeto a los diferentes caminos de construir el socialismo y establecer sus posiciones internacionales"5. El contenido de esta declaración marca una nueva era para la democracia internacional, sobre todo si se toma en cuenta que ese mismo ano se llevaban adelante las investigaciones de los autores materiales e intelectuales de las citadas invasiones, 
especialmente la de Checoeslovaquia, y se realizaba el amplio proceso de rehabilitación de los exilados y eliminados en cada pais en aquellos tristes anos. Se entiende asi el por qué del gran título del foro de Moscú: "el imperio se hace la Perestroika". Pero ¿Porqué Washington no realiza su propia Perestroika? Grenada, Panamá y Nicaragua... algo tendrian que decir, y el big-brother algo tendría que reflexionar. El no a la intolerancia y el si a la democracia es bastante más que discusiones sobre la idoneidad del plan o del mercado.

\section{La Intolerancla del partido único}

Sin lugar a dudas el "no-mayor" a la intolerancia se centra y concentra en la crítica al partido único de vanguardia. Esto es patente en el foro de Moscú, y más aún en los movimientos liberacionistas de los paises periféricos. La sinceridad, por no decir rudeza, de las intervenciones hablan por si mismas; en muchas de sus partes se aplican a nuestro pequeno occidente. La muestra seleccionada es representativa.

"A mi me parece que el estalinismo representaba, no un método de la construcción del socialismo, sino una tentativa bárbara de modernización del pais, de acumulación primaria de recursos en la Rusia atrasada. En esa operación se formó el poder soviético, mediante la apropiación de los derechos del pueblo; y la perestroika consiste en devolver esa propiedad enajenada al pueblo y con ello el propio poder que le pertenece... Vemos, sin embargo, que en el Soviet Supremo son muy pocos los representantes del pueblo que expresan directamente una tendencia radical para la reconquista del poder por el pueblo; y ello evidencia que la lucha acaba de empezar, que la perestroika no ha devuelto, y no puede devolver únicamente con la ayuda de los votos, el poder al pueblo" ... (Anatoli Butenko; historiador, ensayista político, miembro del Instituto Socialista Mundial, defensor de la linea crítica de Gorbachov).

"Atravesamos una crisis profunda de la perestroika. Cuanto más brillantes son algunos informes que se de jan escuchar en el Congreso, tanto más evidente es que el Congreso y la perestroika toparon con un muro ciego: la base del totalitarismo estalinista y del neototalitarismo bresneviano fue la partitocracia de un sólo partido. En nuestro pais, por lo menos a partir de los anos veinte, nunca hubo un verdadero poder soviético, sino sólo partitocracia del partido único; es decir, el poder directo político del aparato no elegido por los veinte millones de miembros del partido no expresaba, ni mucho menos, los sentimientos de este ejército de militantes comunistas... Lo que hay que conseguir 
es que todo el poder, todo el derecho de tomar las decisiones concernientes a todo el pais, pase a los soviéticos elegidos sobre una base democrática"... (Leonid Bajtin; historiador del club-Tribuna de Moscú, y del movithiento democrático; partidario crítico de perestroika).

"Las contradicciones que se dan en el Congreso de los Diputados evidencian precisamente que además de la variante gorbachoniana de la perestroika, ya han nacido, se están formando otras variantes de la perestroika. Los problemas de procedimiento, el orden del día, todo evidencia que dar posibilidad de hablar sin restricciones a los representantes y partidarios de otro enfoque de la perestroika contradice las intenciones del aparato. La perestroika no ha comenzado todavia, y el aparato y las fuerzas vinculadas al antiguo socialismo estalinista le oponen una resistencia feroz. Por eso pienso que nos espera una etapa difícil en la lucha por crear un nuevo tipo de sociedad renunciando al modelo estalinista del socialismo"... (Yuri Afasaniev: historiador, Director del Instituto de Archivos Históricos de Moscú; uno de los líderes de oposición formado en el Congreso de Diputados).

"Si los que toman las decisiones en este pais escucharan to que estamos diciendo en esta conferencia, primero, no nos entenderlan, y segundo, tendrian miedo de lo que estamos diciendo. Esta sociedad que tropieza con su propia muerte no tiene otras vias de conocimiento de lo que pasa, no hay otro camino de salvación, que el de tropezar con la propia muerte; y otra vez vemos en el Congreso a diputados que se escuchan a si mismos, porque queremos que nos vean mejor de to que somos. El diagnóstico también es falso aqui. El diagnóstico se percibe como la causa principal de la enfermedad. Los diputados comprenden que es preciso controlar la reforma política, porque si la perestroika supera o descarta la actual superestructura política sólo entonces será posible solucionar los problemas económicos. En definitiva, todos los planteamientos, todos los diagnósticos tropiezan, quiérase o no, en la necesidad de renovación de esa mayoria no calificada, en el Congreso y fuera del Congreso, que es la que detenta el poder'... (Yuri Kariakin; escritor especializado en Dostoievsky; diputado del Congreso y patidario crítico de la perestroika).

"Me parece que la primera paradoja es la de que el partido comunista fue creado por Lenin con la finalidad de conquistar el poder; pero si la finalidad de la perestroika consiste en construir un Estado de derecho, es evidente que la finalidad del partido comunista, en el sentido gorbachoniano del término, debe ser el de devolver el poder, o al menos compartirlo. Con ello tenemos que una organización disenada para una finalidad deberia servir hoy para prestar un servicio com- 
pletamente opuesto. ¿Es ésto posible?... ¿Cómo se puede poner fin a la lógica de la nomenklatura, a la de-signación política para los puestos de responsabilidad? $Y$ ¿Cómo se puede plantear la cuestión de las nacionalidades, que ya se prevé en la Constitución actual, en un sentido democrático? Y por último ¿Qué piensan nuestros amigos soviéticos de la posibilidad de organizar una prensa auténticamente libre, es decir independiente? Me refiero incluso a la prensa diaria, de la cual tenemos el primer ejemplo de la Europa del Este en Polonia. ¿Es posible algo similar en la Unión Soviética?... (Paolo Flores D'Arcais; sociólogo, historiador y filósofo italiano; director de Micromega, colaborador de La República).

Ojalá que esta acumulación de citas no resulte tediosa; eran necesarias para entender que el problema principal de la perestroika, sobretodo en la URSS, se centra en las resistencias tenaces que una nomenklatura monopolizadora del todo poder político y económico opone a todo signo de reestructuración. En el citado artículo' tratamos de mostrar que éste fue el problema central de ayer y de hoy en las sucesivas perestroikas iniciadas dentro y fuera de la URSS. Sin olvidar todos estos cuestionamientos políticos al interior del bloque socialista, y al mismo tiempo releyendo este serial de citas en el escenario político de nuestros paises, de nuestros procesos electorales, de nuestros debates parlamentarios y de nuestros forcejeos por el manejo del poder, nos sentimos también aludidos por cuanto se ha dicho en este foro de Moscú. Al reducir las reformas del Este a alterantivas de plan o mercado, en nombre de la perestroika seguimos haciendo antiperestroika. Si la democracia es multifacética, también la intolerancia es multifacética y multinacional.

\section{La Intolerancla de la corrupción}

Con la llegada de la glasnot se devela otro género de intolerancia, cuya crítica ha llenado páginas y más páginas. Se trata de la "corrupción" en sus múltiples aspectos. A finales de 1989 la televisión europea sacó a la luz pública el sorprendente juicio, seguido de la rápida ejecución del premier $\mathrm{N}$. Ceaucescu y su esposa, unas reliquias de Estalín en las últimas décadas. Las acusaciones del referido juicio y los relatos procedentes de Rumania en los últimos anos testimoniaban la degradante corrupción interna, los privilegios del equipo dirigente, las arbitrariedades del grupo policiaco, Securitate, la depauperización generalizada de la población civil y el cinismo de la publicidad oficial dentro y fuera del pais. De una u otra forma el drama rumano tenla que terminar en tragedia. En forma incruenta pero preparada a lo largo de 1989 se pone fin en la Alemania del Este, calificada de "demo- 
crática", a la dictadura de Erick Honecker y su odiada policia política, Stasi. Rasgo común en todos éstos secretarios y dirigentes de los pasados partidos comunistas, pronto aparecerán en la prensa, los privilegios de todo tipo con que adomaban su vida privada, pero siempre oculta a los ojos del pueblo. En forma relativamente pacitica se fueron dando los cambios de poder en Polonia, Hungriā, Checoeslovaquia..., y en todos los casos hay un numerador común: el repudio a la cornupción.

Sin duda quien ha fustigado más dura y abiertamente el problema de la cornupción ha sido $M$. Gorbachov en su Perestroika y el precedente Informe al Pleno del Partido (junio, 1987). Vale la pena transcribir alguno de sus párrafos. "Comenzó además una gradual erosión de los valores ideológicos y morales de nuestro pueblo... La presentación de una realidad sin problemas fue contraproducente; se habia formado una brecha entre la palabra y la acción, que produjo la pasividad pública y el descreimiento en los eslogans que se proclamaban. Es natural que esa situación diera por resultado una brecha en la credibilidad: todo lo que era proclamado en las tribunas e impreso en los periódicos y libros de texto fue cuestionado. La decadencia comenzó en la moral pública; los grandes sentimientos de solidaridad con los demás, que se forjaron en los tiempos heróicos de la Revolución, los primeros planes quinquenales, la Gran Guerra Patriótica y la rehabilitación de la postguerra se debilitaban; el alcoholismo, la drogadicción y el crimen crecian, como asi también la penetración de los estereotipos de la cultura popular extrana a nosotros, que produjeron vulgaridad, gustos viles y condujeron a ideologias estériles. La conducción del Partido se relajó y se perdió la iniciativa en algunos de los vitales procesos sociales. Todos comenzaron a notar el estancamiento del liderazgo y la violación de su proceso natural de cambio... El flirteo político y la distribución masiva de premios, nombramientos y bonificaciones, a menudo reemplazaban la genuina preocupación por el pueblo, por sus condiciones de vida y de trabajo, por una atmósfera social favorable. Surgió una atmósfera del "todo vale" con cada vez menos exigencias de disciplina y responsabilidad. Se hicieron intentos de disimular todo con campanas pomposas y promesas y celebraciones de numerosos aniversarios centrales y locales. El mundo de las realidades cotidanas y el mundo de la prosperidad ficticia fueron divergiendo más y más... Los principios de igualdad entre los miembros del partido eran violados frecuentemente. Muchos miembros del partido permanecieron en cargos importantes más allá del control y de la critica, to cual condujo a fallas en el trabajo y a serios actos de incompetencia. En ciertos niveles administrativos surgió un desacato a la ley 
y se fomentó la adulación y el sobomo, el servilismo y la gloriticación. La gente trabajadora estaba justamente indignada ante el abuso de poder, la supresión de la crítica, las fortunas mal habidas, y en algunos casos, incluso, se hizo cómplice o fue organizadora de actos criminales"... (pp. 20-22).

El testimonio de $M$. Gorbachov dice bastante sobre la profundidad y multipolaridad de la cornupción imperante. Por ello "perestroika" significa una "revolución de la revolución" en la URSS. La última alusión de M. Gorbachov "se hizo cómplice, o fue organizadora, de actos criminales", es una clara referencia al iniciado proceso de la "reforma de la justicia". Quien haya leído el Archipiélago Gulag de A. Soljensitsin, o la reciente biografla de Estalin, escrita por Roy Madvedez, se hará cargo de la degeneración (habría que utilizar una palabra más dura) a la que se habia llegado en la aplicación del código penal y civil. Si con Bresnev no se repiten las arbitrariedades judiciales de la era-Estalin, se desarrolla toda la cornupción política y económica propiciadora del estancamiento y desengano generalizado aqui fustigado por M. Gorbachov. De alguna forma el ya citado congresista Yuri Kariakin lo expresa en el foro de Moscú: "Partimos de la idea de que habia que fusilar la democracia burguesa, y con ello fusilamos todo el ordenamiento legal, dejando a la sociedad sin leyes; hay que fusilar la religión, dijimos nosotros, y fusilamos la moral, y el socialismo fue inhumano, por no decir antihumano; y ahora cosechamos los frutos de esas ideas... ¿Por qué nuestra sociedad ocupa hasta ahora el primer lugar en el engano, en el autoengano?"

\section{La Intolerancla del dogmatismo}

Dando forma y consistencia a esta serie de intolerancias se fue desarrollando desde el inicio del socialismo-real otra forma de corupción: el "dogmatismo". Es clara la influencia que en la preparación de Perestroika tiene el "equipo de Novosibirsk", extensión siberiana de la Academia de Ciencias de Moscú. Junto con Abel Aganbegian, llamado el gurú de Gorbachov, hay que destacar la labor crítica de Tatiana Zaslavskaya, Presidenta de la Asociación Soviética de Sociologia. Si en la época-Bresnev estos autores críticos del sistema quedan relegados al lejano Novosibirsk, con el relevo de $M$. Gorbachov se convierten en asesores cercanos del nuevo régimen. Dentro del amplio documento dedicado a la "importancia del factor humano" los sociólogos de Novosibirks destacan la influencia del dogmatismo en las ciencias sociales. "Uno de los obstáculos mayores al avance de la teoria es, sin duda, la persistencia del dogmatismo. Aunque todo el 
mundo reconoce que se trata de algo nefasto, todos somos prisioneros en nuestra vida de estereotipos intelectuales, que utilizamos sin mayor reflexión. La sociología no es una excepción de esta regla. Ella presente numerosos postulados, es decir afirmaciones, que aunque no vengan confirmados por los hechos, no por ello dejan de ser considerado como incontestables y ciertos. De esta manera se afirma que en régimen socialista el trabajo es una necesidad vital, que un elevado nivel de instrucción implica ipso-facto una mejora en la actividad profesional, y que el aumento en las remuneraciones genera un aumento en las remuneraciones genera un aumento de la productividad. Estas proposiciones no son dogmáticas por ser inexactas (de hecho contienen una parte de verdad), sino parque ellas convierten esa parte de verdad en una verdad absoluta. $Y$ ¿qué sucede cuando se confronta la teoria con la realidad? Se ve que para muchos trabajadores el trabajo no es otra cosa que una forma de ganarse la vida, que una mejor instrucción no se traduce necesariamente en un aumento de la productividad... Los dogmas no son inocentes. No sólo se plasman como verdades bien establecidas, sino que entrān en conflicto con las teorias que los pueden amenazar... No sin razón un buen número de investigadores sociales han iniciado la guerra contra el dogmatismo en los viltimos años?.

Es clara la afinidad de esta cita con las palabras de M. Gorbachov: "En las ciencias sociales la teorización escolástica se fomentó y desarrollo. El pensamiento creativo fue expulsado de las ciencias sociales y los juicios y contribuciones superfluos y gratuitos fueron declarados verdades indiscutibles. Las discusiones científicas y teóricas, que son indispensables para el desarrollo del pensamiento y para el esfuerzo creador, fueron castradas..." (p. 21)

\section{Efectos del dogmatismo económlco}

Una de las áreas donde el dogmatismo inventado por la nomenclatura dirigente ha generado lamentables retrasos teóricos y prácticos es el campo de los principios económicos. La segunda parte del Informe de $\mathrm{M}$. Gorbachov al Pleno del Comité Central de Partido (junio-1987) se centra precisamente en la "reforma radical" de toda la organización administrativa. No es por primera vez que dentro de la URSS se intentaron llevar a cabo reestructuraciones económicas con la Perestroika de 1985; pero tuvieron más fuerza los intereses del poder, amparados en dogmatismo económicos, que aún hoy no han desaparecido. Algunas citas pueden servir de ejemplo.

Cuando en los anos de la Nueva Política Económica (NEP, 1920...) 
algunos reconocidos economistas, Kondratief, Groman, Bazarov..., fundamentaban la necesidad de integrar el plan con el mercado en el proceso del lanzamiento del socialismo, fueron reducidos al silencio y luego al exilio. No se utilizó el racional argumento, explicitado por autores de la talla de $M$. Dobb, P. Baran, P. Sweezy..., incluso W. Brus, y fundamentado en las circunstancias históricas de un inmenso pais que debe dar un saldo cuantitativo y cualitativo de economia agrícola a economía sólidamente industrial, en un entorno de aislamiento y oposición europea; en estas circunstancias era necesaria la centralización de todos los esfuerzos y recursos hacia un objetivo social común. Sin embargo la ortodoxia dirigente emite el decreto teórico, según el cual sólo un modelo centralmente planificado y detallado responde, ahora y siempre, a los principios básicos enunciados por los precursores del socialismo científico. Resulta empero, que los precursores del socialismo, en cuanto analistas científicos, nunca intentaron describir anticipadamente un detallado mecanismo de funcionamiento, sino sólo algunos grandes rasgos, del futuro socialismo. Al convertirse en dogma lo que era conveniente en un momento, que sólo un modelo central y detalladamente planificado es socialismo, cualquier intento reformular el sistema será tachado de revisionismo político y sus autores de "social-traidores". Este ha sido el obstáculo número-uno en los repetidos intentos de hacer perestroika dentro y fuera de la URSS. Por ello no le cupo mejor suerte al modelo semicompetitivo presentado, entre otros, por el gran economista Oscar Lange, donde también se integraba la acción del plan y del mercado, los aspectos macro y microeconómicos del cálculo económico, y que veinte anos más tarde pudo haber inspirado la reforma-Liberman.

Por la cercania con los problemas económicos suscitados con la Perestroika conviene hacer una breve referencia a la controversia sucitada ya en la década de 1940 sobre reformulación de criterios en la fijación de los precios y selección de inversiones. Ingenieros de la talla del académico V. Novozhilov, Luria, del premio Nóbel L. Kantarovich... proponian introducir la programación lineal, las evaluaciones objetivas de los costos, los criterios de eficiencia y normas de productividad en la selección de las inversiones..., que frenaran los enormes derroches de recursos y sirvieran de criterios orientadores al Gosplan. También en esta ocasión estos autores se vieron peligrosamente atacados por Voprosy-Ekonomiki (problemas económicos), el órgano oficial del Instituto de Economia de la Academia de Ciencias de Moscú. Las censuras, hoy dia incomprensibles, se centraban en tres puntos. 1) Contravención de la doctrina marxista y de los principios planificadores soviéticos; 2) Perniciosas implicaciones políticas e intento de cornup- 
ción; 3) Errores de razonamiento. La lista de transgresiones ideológicas incluian: estar bajo la influencia de teorias burguesas, recurrir a los conceptos burgueses de la escasez y del margen económico; confianza en la metodologia formal, especialmente matemática, abiertamente divorciada de las leyes y realidades de la economia soviética y aceptación del principio no científico de alcanzar el máximo resultado con mínimo input. La crítica se referia también al uso del interés compuesto; un procedimiento que desatendia la teoria de Marx y de que el interés compuesto era un absurdo, una mixtificación y un disparate. ${ }^{8}$ Habrá que esperar otros veinte años para que la "Mesa Redonda" de economistas y matemáticos soviéticos, 1964, organizada por Voprossy Ekonomiki se puedan discutir estos mismos temas, aunque, L. Kantorovich tenga que soportar los ataques y discrepancias del gran representante de la ortodoxia económica desde los años de 1920, E. Strumilin.

x Con toda razón y con gran disgusto $M$. Gorbachov volverá una y otra vez sobre el tema del derroche de los recursos económicos en su Informe al Pleno del Partido como en Perestroika; se repite por activa y pasiva que "el impulso a la producción bruta, en particular en la industria pesada, se convierte en un objetivo, prioridad número-uno, casi un fin en sí mismo. Lo mismo sucedió con la capitalización (inversión), donde una considerable parte de la riqueza nacional se convirtió en capital ocioso. Se convirtió en algo típico de nuestros especialistas en economia el pensar, no en cómo elevar el activo nacional, sino en cómo colocar más material, mano de obra y horas de trabajo en una partida, para venderla a precios altos. Por lo tanto, a pesar de esa producción bruta, habia escasez de productos. Nosotros gastamos, de hecho estamos todavia gastando mucho más en materias primas, energia y otros recursos, por unidad de producción bruta, que otras naciones desarrolladas..." (p. 18).

Más larga de comentar y no menos seria en sus consecuencias es la deficiente teoria y criterios aplicados a la formación de los precios. En realidad la teoria no tuvo espacio donde moverse, en parte por el lastre dogmático y en parte porque la asignación de los precios era función determinada de los objetivos del plan; no eran los precios los que orientaban al plan, sino el plan quien asignaba los precios. Durante décadas, en las industrias básicas, los precios fijados eran muy inferiores a los costos reales de producción, al igual que los valores asignados a la inversión y a las cuotas de amortización. De ahi el derroche de recursos a que se refiere $M$. Gorbachov, mientras que otros bienes eran subvencionados a cargo del presupuesto estatal. En 1967, con ocasión de la reforma-Liberman, el "comité-Diatchenko" pro- 
pone una tórmula económica de los componentes directos e indirectos de los precios, integrando costos sociales y una referencia a la demanda; pero una vez más este intento es la voz que clama en el desierto, es decir en la fase del estancamiento de la era-Bresnev.

No sin causa M. Gorbachov, más conciso en Perestroika (pp. 99100) y más exahustivo en el Informe al Pleno del Partido se refiere al problema de los precios. "Como esencial parte integrante de la reestructuración económica se presenta la reforma radical de los precios. Sin esta reforma es imposible pasar al nuevo mecanismo. El precio debe desempenar un papel estimulador en cuanto a mejorar el aprovechamiento de los recursos, a reducir los gastos, a mejorar la calidad del producto, a impulsar el progreso técnicocientífico y a racionalizar todo el sistema de distribución y consumo. En este sentido deben aplicarse nuevos enfoques político-económicos, adecuados a la actual etapa de desarrollo... Los precios vigentes siguen creando la ilusión de que los recursos naturales son baratos $e$ inagotables, inducen a incrementar su utilización, consumo y exportación. Los injustificados enfoques que se daban a la formación de los precios trajeron como consecuencia un rápido incremento de las subvenciones a la producción y comercialización de los más diversos artículos y servicios. La suma total de las subvenciones, a costa del presupuesto estatal, rebasa ahora 73 mil millones de rublos anuales"... (Informe; p. 49).

En 1965, luego de una década de más libres discusiones económicas propiciadas por el reformista Krutchev, se inicia la llamada "Reforma-Liberman". Un párrafo introductorio a uno de sus artículos resume los principales objetivos. "Es preciso encontrar una solución que sea suficientemente simple y fundada a uno de los principales problemas planteados por el programa del PCUS: organizar un sistema de planificación y de evaluación de las empresas tal que éstas lleguen a interesarse seriamente por alcanzar metas productivas más elevadas, por adoptar nuevas técnicas y mejorar la calidad de la producción, en una palabra, por obtener la máxima eficiencia productiva" (Pravda; 9sept. 1962). ${ }^{10}$ Quien haya tenido la oportunidad de comparar el discurso de A. Kossiguin, al introducir la reforma-Liberman ante el Pleno del Partido (oct. 1964) y el Informe de M. Gorbachov al Pleno del Partido, veinte años más tarde (junio-1987) podrá apreciar que se trata del original y de la copia de los mismos temas y de los mismos problemas. Y ¿dónde está el problema?

Con suficiente claridad lo expresa el propio E. Liberman en su carta a The Economist, del 31-10-64. "La resistencia que, según ustedes, encontraron mis propuestas en 1962 no se debe a conservadurismo de 
algunos individuos, sino al hecho de que nuestra ciencia económica no ha elaborado suficientemente este complicado problema en su conjunto. Pese a los argumentos de mis adversarios, he tenido la oportunidad de experimentar mis propuestas. Estas posibilidades de experimentación se han ampliado actualmente, pese a la opinión. contraria de algunos economistas, por elevada que sea la posición que ocupan"..." Al momento de escribir estas líneas E. Liberman ignoraba varias cosas. Que su reforma, pese a venir apoyada por numerosos ingenieros, empresarios y miembros de la Academia de las Ciencias de Moscu, se vería bien pronto frenada, no tanto por una deficiente teoria económica, sino por oposición de los adversarios que ocupaban una elevada posición. Ignoraba E. Liberman que, fundados en los principios oconómicos de su reforma soviética, en Checoeslovaquia otro reformista, Ota Sik, inspira la "Primavera de Praga" 1968, que en agosto del mismo ano sería tronchada por la invasión de los tanques rusos. Razón teórica de Pravda: "Checoeslovaquia se está pasando al capitalismo"12. La tercera cosa que no pudo imaginar es que en la primavera de 1983 moria E. Liberman "alone and forgotten".

Pudiéramos alargamos en el comentario al papel meramente pasivo que se ha venido dando a la moneda y al crédito, en su triple aspecto de moneda escriptural, fiduciaria y el problema del rublo transferible pero no convertible. Baste hacer una breve referencia al Informe del $M$. Gorbachov al Pleno del Partido. "Importantes tareas se han de afrontar en materia de finanzas, crédito y circulación monetaria. Sin ello será imposible crear un nuevo mecanismo económco. El problema principal en este ámbito es el desfase entre el movimiento de recursos financieros, crediticios, monetarios y el de los valores materiales, asi como la denominada sobreliquidez. El rublo de hoy no cumple en plena medida su función de medio de control financiero de la economía. Es evidente que el sistema financiero del pais se ha vuelto obsoleto. No estimula la eficiencia $y$, en muchos casos, busca objetivos momentáneos, meramente fiscales. El crédito ha perdido buena parte de su tuerza; los límites que lo separan de la subvención están desdibujados... En el mundo actual ningún Estado puede considerarse oconómicamente aislado de los demás Estados. Nuestro país no es una excepción; la economla soviética forma parte de la economía mundial. Las relaciones comerciales y monetario-financieras intemacionales, los recientes cambios científico-técnicos inciden de una $u$ otra manera, pero inevitablemente, en la economia nacional"... (p. 52...).

Al llegar a este punto parecerla que la conclusión y la alternativa obvia tiene que ser, volvamos a la economía de mercado. Si la perestroika es revolución de la revolución, la salida está en el mercado. 
Semejante interpretación falsearia la finalidad del presente comentario, y sobre todo falsearia la realidad histórica. Si se ha dejado para el último lugar las referencias a algunos errores, notables enrores, del mecanismo de funcionamiento económico en el socialismo real es para indicar que ellos no son la causa, sino los efectos derivados de la concentración política, del poder oligárquico, del dogmatismo a la defensiva, de la simbiósis de poder político y económico que derivó en la multipolar cornupción, y finalmente en el estallido del modelo en la forma e intensidad con que se ha gestado en los paises del Este europeo.

No costaria mucho, porque ya se ha hecho profusamente, redactar un calendario más largo de intolerancias en los modelos económicos donde la oligarquia del poder económico y político se sirve de las "fuerzas del mercado", consagradas como "leyes", para llenar páginas y décadas de intolerancia política, de represión dogmática, de cornupción civica, de derroche de recursos, de inversiones suntuarias, de acaparamiento del crédito, de precios monopólicos, de desprestigio del consumo social, de la venalidad judicial y de acordarse del pueblo en las visperas de las elecciones. No sin razón dice el refrán que los extremos se tocan. En nombre del plan y en nombre del mercado se ha podido desembocar en las mismas intolerancias sociales.

Por ello, la segunda parte del foro de Moscú intenta una nueva convergencia. La introducción al tema de la situación económica es: "A la búsqueda del equilibrio entre mercado y socialismo". Siendo tan diversa la problemática planteada por los ponentes (la inflación, el consumo, el dinero, la agricultura, la forma de propiedad, la economía informal...) juzgo suficiente y conveniente extractar un par de citas de dos economistas, miembros del Congreso. ¿Qué es socialismo?

"El socialismo es una concepción del mundo, un concepto muy amplio del valor de la personalidad; es una visión de la sociedad que da protección social a la persona, que no sólo protege su libertad, sino que le da unas garantias de satisfacción al margen de la aportación del individuo al desarrollo económico del pais... Por eso yo pienso que el mercado, como forma de penetración de la democracia socialista en la economia, es nuestra única posibilidad. El mercado no presupone la explotación, como ocurre en el mercado capitalista.

Es intercambio democrático lo que hace falta. El mercado y el socialismo son dos conceptos compatibles, y yo considero que muchas ideas socialistas no pueden realizarse fuera del mercado. Ahora nos enfrentamos al problema de introducir el mercado cuando se está desintegrando el sistema financiero soviético; es decir, cuando no po- 
demos ir del mercado al mercado" (N. Petrakov; economista de gran prestigio, miembro del Congreso de Diputados, de tendencia reformista).

Más crítico y más cercano a la raíz del problema es el aporte del economista V. Tijinov. "Nuestra estructura económica no refleja la demanda social de productos y este desfase no deja de aumentar. Yo busco las causas, porque ver lo que ocurre es muy fácil. Nuestro sistema económico se ha formado bajo el régimen del monopolio estatal. El monopolio ministerial predomina en las ramas y sectores industriales; se ha realizado la confluencia entre el aparato y los productores, y el consumidor está indefenso frente a los monopolios, no tiene fuerza que le pueda proteger contra los monopolios. Los monopolios dictan su ley al consumidor destruyendo al mercado, dictan al consumidor aquello que no quiere, pero ésto es provechoso para el monopolio... Por eso, junto con las medidas de que habló el profesor Shmeliov, se requiere una violencia administrativa, pero no cruenta. Hay que cambiar las funciones de los ministerios, eliminar su papel de verdaderos detentores de los recursos nacionales, eliminarlos como intermediarios entre el presupuesto y la empresa, y dar a éstas un vínculo directo con el presupuesto. El monopolismo ha penetrado muy hondo en la industria y en la agricultura, ustedes saben perfectamente que la historia de la creación de nuestra industria fue la creación de industrias gigantes, y estos gigantes carecen de movilidad; son gigantes conservadores. Por ello pienso que a la par con el debilitamiento de los ministerios como monopolio, hay que formar un nuevo tipo de producción, basado preponderantemente en las empresas medianas y pequenas, orientadas al mercado y al consumidor. $Y$ es evidente que hay que hacerlo, no sobre la base de la propiedad estatal, sino sobre las cooperativas o de empresas populares. En la agricultura la situación es aún mucho peor. El Estado es propietario monopolista de la tierra, y no sólo acapara los frutos del trabajo del campesino, sino que deja al campesino sólo el derecho de producir aquello que le indican y entregarlo a los precios marcados al consumidor que le mandan. Sólo hay dos caminos para eliminar el monopolio de la tierra. El primero es el arrendamiento universal. Yo fui partidario de este sistema de relaciones... Por eso se requiere otro camino, más radical, vinculado con la desnacionalización de la tierra. Sin desnacionalizar la tierra no cambiaremos las relaciones agrarias para dar al campesino una verdadera independencia económica" (V. Tijonov; diputado del Congreso Soviético; economista muy crítico con la política económica). ${ }^{13}$

Todo este largo serial de citas autorizadas, y no escogidas al azar, asi como las referidas intolerancias muestran que al terminar el siglo- 
$X X$ hay un rechazo, del uno y otro lado, a las diversas manifestaciones del "imperio", traducidas en los monopolios del poder político, económico, dogmático..., de los cuales se derivan el resto de dominaciones y dependencias. Las intolerancias invaden los regímenes del plan y del mercado. Frente a la intolerancia aflora con fuerza una demanda común; la democracia. El gran aporte de la Perestroika de $\mathrm{M}$. Gorbachov es que no termina en la democracia nacional, sino que se extiende a la democracia intemacional: "El mundo entero necesita reestructuración" (p. 229). En esta dirección se enmarca también la macroencuesta europea de 1990.

\section{La macroencuesta europea, 1990}

El foro de Moscú (junio-1989) y las bruscas transformaciones en el conjunto de paises socialistas motivaron la pregunta: ¿hacia dónde va el Este? Con la macroencuesta europea (enero-1990) y debatida en el coloquio de París (febrero-1990) se plantea la pregunta: ¿hacia dónde va el Oeste? Si la nueva-Europa se ha convertido en el centro de la atención mundial no se debe primero ni primordialmente a las expectativas gestadas por un amplio mercado común. Reducir el enfoque a un análisis mercantilistas es privarse de la gran lección y elección sociopolítica que alli se está gestando para Europa y el resto del mundo. El hecho de que se realice una macroencuesta en ocho paises diferentes (RFA, España, Francia, Reino-Unido, Italia, Hungría, Polonia y Rusia) y que los resultados sean debatidos en el coloquio de la Sorbona por treinta representantes de esos países, representa, a la vez, un cuestionamiento del siglo $X X$ que termina $y$ una expectativa del siglo-XXI, que Michel Rocard dice ha comenzado ya en la presente década.

Una encuesta no determina la marcha de la historia, pero pone de manifiesto los deseos y aspiraciones que se espera confirme la historia. En realidad la macroencuesta europea es más que europea y nos sentimos interpelados por las mismas preguntas que alli se plantean. Por ello los resultados estadísticos irán luego acompanados de la interpretación que les den los miembros participantes al coloquio de París.

1) "Los recientes acontecimientos en los paises de la Europa del Este, en su opinión ¿qué vaticinan?

-Ninguno de los ocho paises cree que volverán a un sistema de comunismo tradicional.

- Hay una apreciación general de que "estos paises renunciarán 
progresivamente al comunismo" y evolucionarán hacia regímenes democráticos parlamentarios. Destaca entre todos la opinión bien caliticada de los ciudadanos de Hungrla y Polonia, que en un $76 \%$ y $69 \%$ respectivamente opinan que los sistemas comunistas serán desmantelados. No es está la opinión en la URSSS; $41 \%$ de los encuestados consideran que, manteniendo una organización fundamentalmente comunista, se desarrollarán las libertades políticas y económicas. Sin embargo otro $35 \%$ de los soviéticos apoyan la opinión de húngaros y polacos, a la que también se unen las respuestas de Francia, ReinoUnido, Italia, RFA y Espana, en porcentajes que oscilan entre el 40$50 \%$.

A continuación se solicita especificar más en detalle las opciones económicas y políticas.

2) "Digame si cada una de las palabras que le voy a citar son para usted básicamente positivas o básicamente negativas". Las palabras son: liberalismo, comunismo, socialismo democrático, capitalismo, socialdemocracia.

- La respuesta mayoritaria enuncia: "ni comunismo, ni capitalismo". Sólo los soviéticos confian (38\%) en el comunismo, frente a un $27 \%$ que 10 juzga negativo, y un $35 \%$ que se abstienen. En realidad, las respuestas sobre la valoración del "comunismo" son ampliamente negativas: Espana (55\%); Italia (60\%); Reino-Unido (66\%); Hungria $(75 \%)$; Francia $(79 \%)$; Polonia $(80 \%)$ y RFA $(81 \%)$. Es significativo que en paises donde el partido comunista ha jugado un papel importante salga ahora malparado. En Italia un $20 \%$ lo juzga positivo, frente a un $60 \%$ negativo. Más fuerte es el contraste en Francia, donde sólo el 9\% le da un voto positivo, frente al $79 \%$ negativo.

-Tampoco el "capitalismo sale mucho mejor parado". Los británicos lo juzgan positivo en un $41 \%$, frente al $37 \%$ que lo califican de negativo y un $22 \%$ que se abstiene. Más llamativo es el caso de los polacos, que 10 juzgan positivo en un $42 \%$, ante un $39 \%$ que se abstiene y un $19 \%$ que lo clasifica como negativo; para muchos polacos lo contrario a los soviéticos tiene que ser mejor. En el resto de paises es notablemente superior la valoración negativa del capitalismo, en porcentajes que oscilan del $\mathbf{4 0 \%}$ en la RFA hasta el $52 \%$ en Francia e Italia. Pero hay que notar que es relativamente elevado el abstencionismo en esta pregunta.

¿Hacia obnde se inclinan las opciones político-económicas? Las ponencias del coloquio de Paris ayudarán a entender las siguientes respuestas enmarcadas en un ambiente europeo de rechazo o regimenes totalitarios y partitocráticos. 
3) El "liberalismo", como opción política, es positivamente apreciado por el conjunto de paises encuestados. Sin duda este término tiene una resonancia de libertades políticas, no tanto económicas, pues quienes valoran más positivamente el concepto de liberalismo coinciden, en conjunto, con quienes más negativamente han valorado al capitalismo.

4) "Socialismo y Democracia". Se diría que la Perestroika está influyendo en las mentes y en los ánimos de muchos paises. El concepto de "Socialismo-Democrático" no responde a una realidad existente, pero su idea difusa recibe el beneplácito casi unánime de los ocho paises. Es el concepto, o si se quiere la esperanza, que más votos ha obtenido en la URSS (57\%), frente a un $37 \%$ de abstenciones y un $6 \%$ de voto negativo. Recibe un respaldo cercano al $60 \%$ en Espana, Francia, Italia y Hungria; el Reino-Unido y la RFA le otorgan un $40 \%$ de votos positivos. El polo opuesto a la URSS es Polonia, con un juicio positivo del $30 \%$, un $29 \%$ negativo y un $41 \%$ de abstenciones.

¿Un futuro "socialdemócrata"? A primera vista es una pregunta confirmada por la encuesta. Entre los cinco conceptos evaluados la socialdemocracia alcanza, junto con el liberalismo, los juicios más positivos. Con excepción de la URSS (34\%), el resto de las evaluaciones positivas ronda entre el $50-70 \%$. $Y$ es el concepto que suma menos juicios negativos.

Los resultados hasta aqui comentados no son algo resolutivo, y ello por varias razones que aparecen en la misma encuesta y en el debate de Paris. En primer lugar, los paises del Este europeo, que durante setenta años alguno y otros algo menos, han experimentado sólo un comunismo centralizado, no están en la mejor situación para emitir juicios de valor sobre otros modelos y conceptos sobre los cuales sólo han recibido información indirecta, sea ella positiva o negativa. En los paises del Occidente europeo tampoco resultan muy precisos algunos conceptos y habrá que ponderar más el espiritu que el quantum de las respuestas. De todas formas la encuesta busca precisar estos conceptos.

5) "Conservadores en lo económico, socialdemócratas en lo demás". Esta parece ser la lineal opcional.

5.1) "Al formular la pregunta: cuando usted piensa en la socialdemocracia ¿en qué paises europeos piensa primero?

-Al margen de ciertas coyunturas gubernamentales las respuestas consolidadas los ubican en el siguiente orden: la RFA, el pais más próspero de Europa; le sigue Francia, la segunda potencia europea, y en tercer lugar Suecia, pais de elevada renta per-cápita. Se diria que 
para los europeos la idea de socialdemocracia va ligada a "la abundante generación de riqueza y a la equitativa distribución de la misma". La respuesta debe complementarse con la siguiente pregunta.

5.2) Si usted compara los gobiemos socialdemócratas (Suecia, Francia, Espana) con los gobiernos liberales o conservadores (Kohl en la RFA, Sra. Thatcher en el Reino-Unido), ¿quién, según usted, ha logrado mayor éxito en las siguientes áreas: economia, asuntos sociales, derechos civiles y relaciones internacionales?"

-De acuerdo a la cuantificación de las respuestas (Polonia no responde) los gobiemos liberales-conservadores llevarian la ventaja en la gestión económica; sólo Italia y Espana preferencian la socialdemocracia en este aspecto. Mientras que la socialdemocracia obtiene mejores resultados en el área de los asuntos sociales y los derechos civiles; y sale un poco mejor evaluada que los gobiemos conservadores en el campo de las relaciones internacionales. En estas dos últimas preguntas se aprecia que para algunos encuestados, la RFA juega como socialdemócrata y el gobierno de Kohl como conservador.

La encuesta en cuanto encuesta y la mayoria de ponentes del coloquio de Paris, estarian indicando un "futuro socialdemócrata para Europa". De hecho, la encuesta sigue preguntando" ¿cuáles serian para usted las caracteristicas más representativas de la socialdemocracia? Esta pregunta no se pasó en la encuesta de la URSS. El resto de paises preferencian, en orden de prioridad, las siguientes caracteristicas: seguridad o protección social para todos; la reducción de las desigualdades; la participación de los asalariados en la gestión de las empresas.

Nota curiosa: aunque los paises calificados como socialdemócratas son los más prósperos del continente, sin embargo "un alto nivel de vida" sólo es considerado como caracteristica socialdemócrata por húngaros y polacos. Tampoco el migualitarismo y las elevadas cargas sociales" se identifican entre los rasgos propuestos. Con excepción de Polonia, el resto de paises afirma mayoritariamente que la socialdemocracia es "un sistema para el futuro" y no sólo "un sistema que perteneče al pasado". Esta respuesta recibe nueva confirmación al preguntar a los tres paises del Este (Hungria, Polonia y la URSS): "en el futuro ¿qué regimen preferiria usted para su pais, comunista, socialdemocrata, liberal-capitalista? Las respuestas preferencian mayoritariamente al regimen socialdemócrata:

- Hungria: $53 \%$ socialdemócrata; $24 \%$ liberal-capitalista

- Polonia: $\quad 44 \%$ socialdemócrata; $27 \%$ liberal-capitalista

- La URSS: $35 \%$ socialdemócrata; $31 \%$ comunista 
6) La parte final de la encuesta se dirige a los tres paises del Este, ya mencionados, y su reacción es bien iluminadora. "Qué es to que usted más espera de los paises occidentales?" Ordenando las respuestas, se preferencian las siguientes expectativas económicas y políticas:

- Que construyan conjuntamente con nuestro país un mercado común europeo.

- Que sus empresas inviertan en nuestro pais; que concedan créditos a nuestro pais.

- Que reduzcan sus gastos militares.

- Que ayuden a nuestro país a aprender mejor las reglas del pluralismo político.

- Que presionen para que tengamos mayores libertades.

Estas respuestas finales vendrian a confirmar lo expuesto en la primera parte del presente comentario.

7) Hay un punto de especial importancia para los europeos encuestados dentro de la gestación de la "nueva-Europa"; se trata de la unificación alemana. La encuesta pregunta: "Personalmente, ¿está usted a favor o en contra de la reunificación alemana? Consciente o inconscientemente se ha utilizado un vocablo no muy idóneo, al referirse a la "reunificación alemana", que puede sonar más a tiempo pasado que a tiempo futuro.

- Las respuestas, en su mayoria, se ordenan entre el "bastante a favor y el totalmente a favor", conjugando entre el $50 \%$ y el $80 \%$ de los votos favorables. Hay una comprensible excepción: Polonia vota $38 \%$ totalmente en contra y $26 \%$ bastante en contra. Es claro el miedo a la reunificación y al posible traslado de fronteras. En el coloquio de París, el excanciller Willy Brandt sale al encuentro de ambos temores. "He leído las encuestas de opinión y debo decir que pienso que no hay que tener miedo a la unidad alemana. Fijense que no digo reunificación; la reunificación no está en la orden del dla. No habrá un cuarto Reich. No habrá modificación de fronteras. Está fuera de duda que no se pondrá en cuestión la frontera germano polaca"... Y B. Geremek (del movimiento de Solidaridad) agradece a Willy Branot "por su distinción entre unidad alemana y reunificación de una vieja unidad política". Sobre este tema volveremos a comentar el coloquio de París.

8) Completando la visión de la nueva Europa, y en conęxión con la anterior pregunta, se solltita de los encuestados su opinión sobre "el posible porvenir de paz o de conflictos a raiz de la evolución actual de 
los paises del Esten. Hay que decir que las apreciaciones resultan un tanto dispares. Son totalmente minoritarias las opiniones de quienes juzgan que "se podria provocar otra tercera guerra mundial". Sin embargo tres paises, Francia, Reino-Unido y Polonia, en proporción de un $50 \%$ piensan que "no se eliminan realmente los riesgos de conflicto en Europa". En algunos de los encuestados pesan sin duda los recuerdos de la última guerra, amén de la guerra fría. No asi en el resto de paises: alemanes, espanoles, italianos y húngaros juzgan en su mayoria que esta evolución garantiza un proceso de paz duradera en Europa. $Y$ un $30 \%$ de franceses, ingleses y soviéticos se suman a esta visión más optimista. Se diría que la paz tiene más votos que los riesgos de conflictos, aunque sirvan de materia prima para películas del futuro.

\section{La macroencuesta europea en el coloqulo de París}

¿En qué nos puede servir, habitantes de Centroamérica, una encuesta y un coloquio europeo? Consciente 0 inconscientemente todos hemos respondido a esta encuesta y ponemos nuestra fe en determinado modelo económico. Se dice "nuestra fe", porque convertimos en religión, en algo que nos ata, a cada sistema o modelo económico. Pero también existen quienes han perdido la fe en su sistema o modelo económico; existen los decepcionados por cualquier partido político que busca el poder. La historia comparada de los partidos políticos les ha ensenado que todos prometen mucho y pocos realizan las promesas. Si en la encuesta unos responden positivamente y otros negativamente, no hay que olvidar el buen grupo de los que se abstienen, quizás porque han perdido totalmente la fe en la política, o tal vez porque no aparece en la encuesta el movimiento que ellos apoyan.

Es notorio que en la nueva-Europa hayan aparecido tantos movimientos nacionalistas, ecológicos, tantas nuevas agnupaciones en clandestinidad y en oposición. Las alternativas clasificadas en la macroencuesta no encierra todas las posibles elecciones, no dan cauce de expresión a todas las expectativas de los encuestados. Además, los mismos conceptos (comunismo, socialismo, capitalismo, socialdemocracia...) tienen resonancias diferentes de acuerdo a las experiencias vividas por cada uno y de acuerdo a las expectativas que se imagina. Para comenzar hay un problema de terminología. Pero en el caso de la nueva-Europa hay algo más cercano a nuestro caso. A la nuevaEuropa se le está mirando como un nuevo gran mercado común; las dos Alemanias ya están firmando y parlamentando un tratado económico-monetario. Pero esta visión mercantilista, hecha desde la óptica de la inversión, del crédito, del rendimiento, es cierta pero no completa. 
La nueva-Europa será un mosaico compuesto de hombres distintos, de nacionalidades emergentes, de historias enfrentadas, de aspiraciones a veces semejantes y a veces encontradas. Lo que unifica a todos ellos es que son hombres y naciones en búsqueda de algo nuevo. Por algo dicen que ahora, en 1989 ...,comienza el siglo XXI. Ahi nos situamos nosotros: somos hombres y naciones en búsqueda, queremos algo nuevo que tal vez no aparece en la macroencuesta, algo más que to económico del plan o del mercado; nos sentimos con derecho a iniciar un nuevo siglo XXI. El coloquio de París nos puede ayudar a montar nuestro propio coloquio.

Entre la multifacética temática hay que seleccionar lo más afín a nuestro propósito. Si la pregunta inicial era: ¿hacia dónde va el Este?, los ponentes de la Europa oriental cuestionan ¿hacia dónde va el Oeste? Para ser companeros de ruta son las dos Europas quienes van a dialogar sobre la dirección y la intención del camino a recorrer. El Este caminará hacia el Oeste si el Oeste camina hacia donde quisiera llegar el Este. ¿No será esa misma nuestra aspiración cuando se nos quiere imponer la velocidad y el camino a seguir?

Para comenzar, el Primer Ministro del pais anfitrión, Michel Rocard trata de esclarecer un problema de terminología. "Los comunistas en el Oeste, y más todavia en el Este, quisieron apropiarse de la noción misma de socialismo, aunque lo que en el Oeste denominamos socialismo quiere decir socialdemocracia, sociedad pluralista, economía compatitiva y diversificada, protección social; y lo que se presentaba en el Este como socialismo significa para nosotros comunismo. Es pues importante establecer la veracidad de las palabras". Para marcar estas discrepancias de terminología se viene utilizando la expresión socialismo-real, al referirse a las economias del Este; y se plantea la pregunta: esas economias ¿son socialistas?, ¿han sido alguna vez socialistas y podrán llegarlo a ser algún dia? Si hay un problema de terminologia, hay un problema más importante de contenido.

Andrei Grachov (economista soviético, jefe del Departamento Internacional en el Comité Central del Partido Comunista de la URSS) expone asi el problema de la terminología y del contenido. "Venimos del pals del socialismo real, que ha sido a veces un socialismo irreal, 0 incluso más que real ya que albergaba la ambición de estar por encima de la realidad y del realismo. Hay que decir que este socialismo ha' fracasado. Lo decimos entre nosotros y lo reconocemos ante ustedes. Pero una cuestión permanece abierta: ¿este fracaso es del socialismo en cuanto tal, como ideal, como ambición, como orientación de la evolución de la sociedad, de la humanidad, o se trata de un fracaso 
particular, preciso, desdichado, condicionado por las condiciones particulares de Rusia". Esta intervención de A. Grachov, que rezuma sabores de Perestroika, explica por qué al interior de la URSS el más elevado porcentaje de votos (57\%) se to llevó el socialismo-democrático. Se sabe lo que hay que quitar; se busca to que hay que construir.

Groogry Gysi (Secretario General del renovado partido comunista de la Alemania Oriental, PDS: partido para el socialismo democrático) inicia su exposición con el mismo tema. "El socialismo llamado real, el socialismo autoritario y burocrático, ha caducado como concepción social. Esta concepción ya no tiene salida, pero eso no quiere decir que no la haya para la República Democrática Alemana (RDA) o para los demás paises de la Europa Oriental". Michel Rocard, tomando el agua de más amiba, plantea la oposición de contrarios". Desde el golpe de estado bolchevique, los principales dirigentes de la lla. Internacional, León Blum, Karl Kaustky y tantos otros dijeron to esencial: que el voluntarismo de Lenín sólo podía conducir a una dictadura duradera sobre el proletariado; que sólo la democracia política permite conocer la voluntad popular; que la democracia no puede ser sólo un medio sino un fin. La oposición que de ahi derivó entre el comunismo y el socialismo fue irreductible en el fondo". Seria supérfluo agregar nuevos testimonios de otros ponentes que abundarian en la misma línea de terminologia y de contenido.

Más cerca de nuestra sana curiosidad es escuchar el planteamiento que, línea seguida, hace el mismo G. Gysi. "Para ellos (los paises de Europa Oriental) existen dos posibilidades; el socialismo democrático, que implica una sociedad libre y democrática, eficaz económicamente, pero también con unas responsabilidades asumidas en el terreno ecoKógico y social. Esta idea no tiene que ver con el tipo de socialismo estalinista que se acaba de hundir en el centro y en el este de Europa. El otro camino, que aqui se ha definido como via liberal o como Economia Social de Mercado, funciona bien y en beneficio de los ciudadanos sólo en pocos paises. A pesar de la economía de mercado, la mayor parte de la humanidad vive en la más profunda pobreza. Su formula es que unos pocos paises viven bien a expensas de otros muchos".

¿Significan estas palabras una idealización de la socialdemocracia y un voto negativo a la economía social de mercado? No va por ahl la tesis del ponente, ni tampoco la realidad es tan simplista. La macroencuesta europea parece indicar una línea media: conservadores en to económico, socialdemócratas en lo demás. En uno y en otro modelo 
queda bastante por avanzar, a juicio del mismo G. Gysi. "Las declaraciones y los programas de los partidos socialistas y socialdemócratas en Occidente reconocen que el socialismo democrático, al que aspiran, está lejos de haber sido realizado... "Igualmente anade: "Una restauración de la economia de mercado que desembocase finalmente en la dominación de los intereses del capital y de las grandes empresas privadas, reemplazaria, a mi entender, una dependencia antigua por otra nueva".

G. Gisy toca un aspecto radical de la presente evolución: el mercado puede convertirse en un instrumento de dependencia semejante a to realizado por el plan. Mercado y plan no aparecen como dos atternativas opuestas, sino como dos posibles sustitutos. "No obstante, la República Democrática Alemana tiene sus propias conquistas sociales y debemos procurar que no se pierdan en la aproximación con la República Federal de Alemania. Necesitamos en la RDA una economia social de mercado, pero necesitamos evitar su lado sombrio y debemos conservar los derechos sociales. Aqui incluyo el derecho al trabajo, la satisfacción de las necesidades vitales y sobre todo la igualdad de la mujer... No se puede decir hoy si la RDA se encamina hacia un socialismo democrático o hacia una economía de mercado orientada hacia el provecho de unos pocos. Pero, si se realizase esta segunda opción, estos hombres aportarian a esta sociedad su deseo de justicia social"...

Los modelos económicos no se forman en los libros de textos, muy hábiles en hacerles cinjía plástica, sino que van conformando su imagen en una historia concreta; ello atane también a la misma socialdemocracia. Bronislav Geremek (jefe del grupo parlamentario del movimiento solidaridad, historiador) presenta otra faceta de esta evolución. "El problema de la transición se plantea en Europa Oriental de manera árdua, y eso concierne tanto a Polonia como a Hungria, Rumania y la República Democrática Alemana. La tendencia socialdemócrata ocupa ahora cierto lugar en las mentalidades de la Europa del Este, pero hay que ver también todo el peso que impide, todavia hoy, que se haga una profesión de fe en la socialdemocracia. No hay que olvidar que no ha sido sólo la experiencia del socialismo real to que ha comprometido la palabra y en cierto sentido la realidad del socialismo; ha sido cierto modo de relaciones entre los partidos socialistas y los partidos socialdemócratas de la Europa Occidental con los paises del Este to que pesa sobre la manera de apreciar -en Europa Oriental - la palabra socialista y el movimiento socialista... hay que ver también los comportamientos de los partidos socialistas y socialdembcratas que pretendian tener relaciones privilegiadas con el 
partido comunista en el poder... En otras palabras, B. Geremek recuerda que pasadas alianzas de gobiemos comunistas y socialistas del Este y Oeste siguen siendo un obstáculo para una espontánea aceptación de la socialdemocracia. Por ello el ponente polaco pasa a tratar el tema de los movimientos nacionales y el peligro de nacionalidad, problema sobre el que versarán todos los ponentes del coloquio.

Antes de refirnos al problema de los rebrotes del nacionalismo conviene regresar a la estructuración de la misma macroencuesta. ¿Estaba bien planteada la encuesta europea de suerte que los cinco conceptos alternativos fueran asequibles a los encuestados del Este europeo? No se trata de un problema conceputal, sino de inexistencia histórica de la mayoría de esos modelos económico-políticos al interior de los regímenes comunistas. Serán sobre todo los participantes húngaros y polacos quienes planteen este problema. Janos Kis (dirigente del movimiento Alianza Democrática de Hungria) se hace la pregunta: ¿¿qué partidos llenarán el espacio político abierto por la democratización? Creo que esta cuestión es extremadamente importante y no sólo porque la respuesta decidirá el carácter de la democracia caso por caso. Sino porque no sólo debemos crear un sistema democrático sobre las ninas del totalitarismo, sino también reintegrar o reunificar por primera vez Europa como entidad política o suprapolítica... Se dice que una misma tendencia, la de la socialdemocracia, parece ser dominante tanto en el Este como en el Oeste europeo. Esta conclusión me parece estimulante, pero un poco pretenciosa. A priori pensaria que tras una interupción de treinta anos de tradiciones política, que no siempre se entroncaban con la misma tradición política moderna, no es muy probable que encontremos la misma estructura de valores políticos y las mismas sensibilidades en el Este y en Oeste... Sobre todo que salta a la vista que el partido socialdemócrata figura aqui (en la macroencuesta) en una lista de partidos que no existen en Hungria a la hora actual. Esta lista es de partidos virtuales, y el partido socialdemócrata, que figura en esta lista, no es un partido actual; representa para el interrogado sólo una virtualidad... El tercer problema es el de que, al menos en determinados paises de la región, el espacio político está ocupado por movimientos más recientes, por organizaciones que extraen su legitimidad de una tradición que nada tiene que ver con la socialdemocracia o el movimiento democristiano, partidos liberales, etcétera. Se trata de Solidaridad en Polonia, Forum en Checoeslovaquia, y en Hungria La Alianza Democrática, heredera de la oposición democrática de $1970 \ldots$ Pero en estos momentos es difícil situar estos movimientos en relación con Occidente". 
Los dos representantes polacos, del movimiento Solidaridad, subrayan la misma dificultad de querer engarzar estos movimientos nacionales en los esquemas políticos occidentales. Adam Michnik (parlamentario polaco, director del diario de Solidaridad) b expone didácticamente. "Refiriéndome al caso de Checoeslovaquia diré que esta admirable revolución sin violencia, que ha establecido el pluralismo, no se ha clarificado suficientemente. Los primeros pasos se han dado a partir de la nostalgia, al igual que en Hungria. Occidente debe estar muy contento de que existen una derecha y una izquierda tradicionales, pero hablar de partidos que hasta un ano no han existido no es serio, es una mascarada. También hemos de ser serios en lo que concieme a Polonia. Polonia es un pais católico. El partido cristiano, que se ha fundado hace un año, no existe realmente. ¿Por qué? Esto supone, a mi entender, la crisis de la escena política tradicional. Si el escenario político occidental es el resultado de una revolución burguesa, el nuestro será, creo, el resultado de una revolución antitotalitaria, ¿cuál será? no lo sé. Pero sus categorias no son útiles para analizar la situación en la URSS, Polonia, Hungria, etcétera. Lo interesante es to que nos une, las estructuras de la dictadura política. Quiero declarar sólo que nuestra actitud es análoga a la formulada por los socialdemócratas suecos: estamos a favor de la economía de mercado, pero una economia de mercado de rostro humano"...

Dando un paso más allá, el modo totalitario de hacer política ha engendrado el miedo a la misma politica; tal es la tesis de B. Geremek. "La política, tal y como se ha venido practicando durante decenios, es un monopolio del poder. El resultado ha sido el rechazo en bloque de la política, del fenómeno partido-político. El partido político en nuestros países, sigue siendo un fenómeno que se contempla con desconfianza y temor. Pero, puesto que pensamos que 1989 es la apertura de este nuevo siglo ise abren acaso perspectivas nuevas que permitan articular la escena política? Acaso, al lado de los partidos deban aparecer movimientos como el mío. Solidaridad, que es una fuerza política centrada en torno a valores éticos y no a la lucha por el poder. Se puede columbrar ahi no sólo la desconfianza respecto al fenómeno de los partidos, sino acaso también uno de los signos de la evolución futura. Me atrevo a decir, aun pecando de optimista, que después de la felicidad que nos ha traido 1989, esa Europa, que busca hoy estructuras comunes, debería ver con realismo no sólo lo que preocupa a los europeos del Este, sino a todos los europeos, en general, algo que puede poner en peligro a toda Europa". ¿Serán los partidos político?

Si la búsqueda del poder puede deformar nacionalmente los objetivos de todo partido político, a nivel internacional o macroeuropeo se 
cieme otro peligro, quizás el más comentado y más atendido en el coloquio de Parls. Hemos titulado este comentario: ¿hacia donde va el Este y hacia obnde va el Oeste? Para caminar juntos tienen que encontrarse y para formar una Europa unida hay que unir las diferentes partes. Dos obstáculos previsibles: que el oeste se sienta el anfitrión que recibe y adopta al Este con aires de superioridad, Segundo, el peligro de los rebrotes del nacionalismo y de las nacionalidades. Otro aspecto de la realidad europea que nos atane muy cerca como habitantes de un mercado común dislocado, pendientes y dependientes de otros centros dominantes.

El representante de Solidaridad, B. Geremek, expone claramente el problema. "Los temores que se sienten en Europa del Este se expresan de manera diferente, con un cierto reflejo de autodefensa. Un reflejo nacional que se convierte en uno de los grandes peligros que acechan a toda Europa. En una palabra el peligro del nacionalismo. Este peligro se halla presente en todas nuestras sociedades postotalitarias del Este y del Oeste. Pero pienso en el porvenir de algunas actitudes de la Europa occidental. Los comportamientos xenófobos y de miedo respecto del pobre europeo oriental que llama a la puerta del Occidente opulento. De esta forma, el temor define de manera nueva la vida en Europa oriental. La instauración de un mercado para millones de personas habituadas a la economia planificada-donde habia una cierta estabilidad en la miseria-introduce la incertidumbre, la incertidumbre del cambio. Lo que se puede convertir en un obstáculo al cambio en Europa oriental es la apatia y el temor de la política"...

Los rebrotes del temido nacionalismo tienen raices diversas. El excanciller Willy Brandt senala como causa posible la misma competencia y cooperación de fuerzas en la construcción del nuevo continente, que será un mercado altamente competitivo, sin lugar a prácticas extranas del dumping. "Creo que los años futuros serán el escenario de un combate entre elementos resurgentes del nacionalismo extremo y de las nuevas fuerzas de la cooperación europea". En este marco competitivo, no hay duda de que la unificación alemana puede derivar al más temido nacionalismo. Los representantes alemanes senalan el problema y salen al encuentro del miedo europeo.

G. Gisy se dirige a alemanes y a europeos. "La unidad'no debe asustar a los ciudadanos de la República Democrática Alemana. Habrá que respetar los intereses de los cuatro aliados y los intereses de los pueblos vecinos como los polacos. Un eventual nuevo nacionalismo es inaceptable para encarar la unidad alemana. La unificación alemana debe inscribirse en el proceso de la unidad europea y contribuir a la 
creación de to que en palabra del Presidente Mitterrand será una confederación europea. Para finalizar diré que este proceso de unidad está alumbrando una Alemania europea y no una Europa alemana. No necesitamos intereses de grandes potencias, ni un nacionalismo 0 chovinismo granalemán. Estoy convencido de que las ideas del socialismo democrático formarán una barrera en el camino del nacionalismo alemán. En todo momento nos esforzaremos para que los intereses alemanes se encuadren dentro de los intereses europeos de seguridad y de paz".

Los rebrotes del nacionalismo en el mismo proceso de la integración como frutos de recuerdos pasados o de recientes experiencias totalitarias. Asi lo advierte y 10 previene Michel Rocard. "Esta diversidad nacional inspira a veces inquietud. La idea de que podría renacer la Europa anterior a 1939, o bien la Europa anterior a 1914, es evocada a menudo. No podemos ignorar este interrogante. Su peso podría alejar las opiniones entre sí. Pienso que se debe expresar la voluntad de los pueblos que se han visto incluidos, muy a su pesar, en un sistema imperial, al tiempo que se han visto privados de su soberania política. El sentimentalismo nacional ha sido utilizado a menudo como un instrumento de resistencia al totalitarismo. Pero este movimiento que lleva a la reapropiación de una cultura nacional no debe degradarse en nacionalismo. Es preciso que todos juntos, y por primera vez en nuestra historia común, cobremos conciencia de que no puede haber contradicción entre la Europa unida y las naciones que la componen. No hay lugar en Europa para una dominación imperial"...

Jorge Semprún (Ministro de Cultura en el gobierno socialista espanol) introduce un nuevo elemento, que también lo tocara de paso Willy Brandt. "Mi tercera observación concierne al peligro de los extremismos nacionalistas y religiosos, sobre todo los extremos nacionalistas. Empecemos por el principio. Digamos que la extraordinaria necesidad de afirmación de la identidad nacional es uno de los componentes iniciales de la resistencia y posteriormente de la afirmación democrática. El zarismo fue la prisión del pueblo, el estalinismo lo multiplicó no se por qué factor. Pero ¿dónde establecer la frontera entre la necesidad absolutamente ineluctable, imperiosa y democrática de la afirmación de la identidad nacional y del peligro nacionalista? Se trata de un problema que hay que resolver en la práctica, en el pragmatismo de la acción. Lo mismo diré respecto de la afirmación de la fe, sea católica o protestante en todos los paises en que ha jugado un papel. Polonia es un caso particular de to que digo. Tenemos en Occidente una tradición laica y crítica que es justa y necesaria, que se remite a los valores universales, pero hay que comprender el papel que la Iglesia ha tenido 
en la conservación de la identidad nacional. Por ello atención, cuando se manipulan de manera desconsiderada los peligros extremistas del nacionalismo. Atención, porque corremos el riesgo de separarnos de una parte importante de las fuerzas democráticas del Este de Europa"...

Sólo dos testimonios más para cerrar el tema nacionalista. El húngaro Janos Kis termina asi su ponencia. "Quiero referime finalmente a la cuestión del nacionalismo. Hay que afrontar de manera concreta los problemas no resueltos, y concretamente el de que el destino de la democracia húngara dependa de la democracia en un país vecino, Rumania... Pido a quien se crea demócrata y europeo, rumano, húngaro o polaco, serbio o croata, búlgaro, ruso o francés, que no olviden trabajar por una Europa en que las fronteras sean hoy aceptadas por todo el mundo, precisamente porque hayan perdido su importancia".

Adam Michnik, luego de hacer su profesión de fe católica, invita a una confesión general del pecado de xenofobia. "Hay que preguntarse también si un orden autoritario, chovinista, fascistizante es posible en Europa Central. $\mathrm{Si}$, creo que si, y hay que decirlo abiertamente: es posible. Porque después de la derrota de las ideologias socialistas, tras la derrota de los simbolos de la izquierda, hay un vacio y la reacción natural es el retorno a las raices de la identidad elemental. No hay que definir todas las luchas nacionales de la Europa Central como chovinistas. Pero hay que comprender que las luchas nacionales tienen unas consecuencias muy ambiguas. El resultado es la libertad, pero también la xenofobia. Me he puesto algo nervioso al ecuchar a todos los intelectuales. Yo creia que Willy Brandt, el líder de la lla. Internacional se pronunciaria contra las manifestaciones antipolacas de Leipzig, contra las consignas de "Polacos, fuera", escritas en las paredes de las ciudades alemanas, pero no to ha hecho. Hay que terminar con estas prácticas. Me pronuncio contra todas las acciones antigermánicas, antilituanas, antiucranianas en mi patria. Estoy seguro absolutamente de que este movimento de xenofobia, de odio nacional, sería una catástrofe para toda Europa Occidental. Este es el problema más dramático y complicado de toda la Europa contemporánea. En este contexto podemos declarar abiertamente que somos culpables y debernos decir algo contra nuestro corazón y no contra el corazón de nuestros vecinos"...

Hasta aqui llegaria el extracto de algunos temas debatidos en el coloquio de París, que no descalifica sino profundiza el significado de- 
mocrático de las respuestas encasilladas en la macroencuesta. Las citas literales ${ }^{14}$ obedecen a un propósito de autenticidad, donde el lector no se vea mediatizado por el subjetivismo de quien escribe. Los tres eventos aqui referidos (foro de Moscú, macroencuesta y coloquio de Paris) tienen sin duda una calificada autoridad al emitir un juicio de valor sobre el siglo XX que termina y del siglo XXI que se desea iniciar en un escenario más democrático. Era preciso deslindar las obscuridades de la terminologia, llamar a las cosas por su nombre; pero de manera especial era necesario poner fin a los dogmatismos de signo maniqueo, del todo bien frente al todo mal. En vez de mirar la historia desde los manuales clásicos, hay que rehacer las teorias desde la historia concreta del siglo $X X$, a fin de que no se repita en el siglo XXI. Del mismo modo, resumir los problemas y los cambios realizados en el Este a un simple viraje de modelo económico es quedarse en el "far-west", es decir en la esquina de to que sucede en el mundo.

Cuando M. Gorbachov dice: "más socialismo, más democracia" no está pidiendo que nos hagamos más socialistas, porque este concepto no cuenta con el parabién de todos; lo que nos está pidiendo es que nos hagamos más demócratas, y el resto se nos dará por anadidura. Pero, ¿qué es democracia? Algo hemos aprendido, porque democracia son muchas cosas. Son elecciones libres con parlamentarismo pluripartidista. Son partidos políticos junto a movimientos nacionales. Es un mercado común integrado por naciones libres. Es el respeto a to nacional en el respeto internacional y también al revés. Puede ser economía social de mercado sin monopolios y desigualdades sociales. Son las necesidades vitales con la seguridad social para todos. Democracia es libertad para la verdad y cauces para que todos puedan llegar a la verdad. Democracia es respeto a los derechos de los demás en lo político, en lo económico, en lo cultural y también en lo religioso. Democracia es lo contrario al individualismo, al totalitarismo, al partidismo, al dogmatismo cerrado y de manera especial al imperialismo de las armas... El coloquio de París nos ofrece puntos de agenda para un coloquio centro y norteamericano, porque el Este y el Oste quieren ir hacia la democracia.

\section{NOTAS}

1. Michel Rocard: "El Siglo XXI ha comenzado ya". En temas de nuestra época: El Este va al Oeste. El País, Madrid; 22-marzo-1990; p. 6.

2. N. Kondratief, famoso economista ruso y analista del capitalismo, descubrió y explico la formación de estas ondas largas del capitalismo 
hasta 1930. En los ahios de 1920, cuando se discutla la Nueva Política Económica de Lenin, defendió junto con otros economistas la necesidad de integrar el Plan con el Mercado en esa economia socialista. Esto lo malquistó con Stalin, quien to hizo desterrar a Siberia. Su nombre aparece en la página 52 del Archipiélago-Gulag.

3. Ficha técnica de la macroencuesta europea:

\begin{tabular}{llrr|r} 
Palses & Institutos & Muestras & Fechas-encuesta \\
RFA & Basic Research & 914 & $17-30$ Enero-90 \\
España & ECO & 1.000 & $8-12$ Enero-90 \\
\hline Francia & CSA & 1024 & $8-12$ Enero-90 \\
Reino Unido & MORI & 901 & $18-22$ Enero-90 \\
Halia & Research Internat. & 1.000 & $8-17$ Enero-90 \\
Hungrla & Median & 1.193 & $19-26$ Enero-90 \\
Polonia & Demoskop & 997 & $9-17$ Enero-90 \\
URSS & Instit. Opinión Pública & 969 & $5-14$ Enero-90
\end{tabular}

4. Hisate Fco. Javier: "La post-perestroi,a on el bloque socialista y su repercusión en nuestro tercer-mundo". ECA, abril-1990.

5. Tertsch H.: "La muerte de la doctrina-Bresnev". El Pals; 11-5-88; pág. 4.

6. "Temas de nuestra época". El Pals, Madrid: jueves, 3-agosto-1989; pp. 116.

7. "Problémes Politiques et Sociaux". La Documentation Francaise"; oct. dic. 1986; pp. 5-6.

8. Grosman G.: "La escasez de capital y la doctrina soviética"; pp. 218-19.

Campbell R.: "La matemática on la planificación soviética y la toorla del valor" p. 140.

Leontief W.: Decadencia y ascensión de la ciencia económica soviética"; p. 131.

9. "Una Mesa Redonda de oconomistas y matemáticos soviéticos". En "Planificación del Socialismo". Oikos. 1967; pp. 43-95.

10. Liberman E.: "Plan, beneficio y primas". Plan y Beneficio on la Economla soviética". Arias. 1969; p. 19.

11. Liberman E.: Carta de E. Liberman a The Economist. Ibidem; p. 191.

12. Sweezy P. y Bettelheim Ch.: "Algunos problemas actuales del socialismo" Siglo XXI. 1973; pp. 12.

13. El Pais. Temas de nuestra época. 3-agosto-1989; p. 7 y 9.

14. Los datos de la macroencuesta europea aparecen on El Pals, 19-2-90. El coloquio de Parls. El País. 22-3-90. Temas de nuestra época; pp. 1-12. 